\title{
Optical, Electrical and Structural Properties of Zinc SelenideSemiconductor Nano Films Deposited by Electrodeposition Technique.
}

\author{
Igwebuike, $\mathrm{H}$. N and Okoli, D. N. \\ Department of Physics and Industrial Physics, NnamdiAzikiwe University, Awka, Anambra State, Nigeria.
}

\begin{abstract}
Nano films of zinc selenide were deposited on well cleaned fluorine doped tin oxide (FTO) glass substrate using electrodeposition technique. The deposited films were optically, electrically and structurally characterized using M501 UV-visible spectrophotometer in the wavelength range of 300-900nm, MT345 fourpoint probe and X-ray diffractometer respectively. The experiments were carried out at room temperature (300K).The results show showed that zinc selenide is a direct band gap type semiconductor with band gap energy of 2.5eV and high refractive index value of 2.18-2.64. The deposited films exhibited a cubic structure with preferred orientation along (111) plane. The lattice constant was also found to be $5.852 \AA$. The grain size, dislocation density, and micro-strain values were found to be a function of voltage and time of deposition. The sheet resistivity was also found to be high with low conductivity values. All these desirable properties made the material to be a good candidate for application in photovoltaic andopto-electronic devices.
\end{abstract}

Keywords: Nanofilms, FTO, Electrodeposition, four-point probe, XRD, grain size, bandgap energy dislocation density, micro-strain and refractive index

\section{Introduction}

Extensive research has been devoted to grow various kinds of binary semiconductor thin films [1]. This is due to their potential applications in the area of solar cells, optoelectronic devices, photoconductors, sensors, thin films polarizes, thermoelectric cooling materials and infrared detector devices. Zinc selenide are being investigated largely because of their potential for new technological applications as well as their scientific interest. Their size-dependent properties make it possible to change the wavelength of band-to-band transitions permitting emission in the green, blue, or even UV region of the light spectrum [2]. ZnSe is an interesting II-VI semiconducting material, widely used in optoelectronic devices, because its bandgap ( $2.7 \mathrm{eV})$ belongs to the visible region [3]. ZnSe can be synthesized by many methods such as chemical vapor deposition [4], molecular beam epitaxy, atomic layer epitaxy, pulsed laser, metalorganic chemical vapor deposition, and sputtering [5]. In this paper electrodeposition technique was used to deposit zinc selenide semiconductor thin films onto a glass substrate (FTO) toinvestigate the structural, electrical and optical properties of zinc selenidenano films. Several researchers have grown zinc Selenide ( $\mathrm{ZnSe}$ ) by using different techniques. However, the several author's reports are often silent on the electrical properties of ZnSenano films.

\section{Materials And Methods}

Zinc Selenidenano films were prepared by electrodeposition technique onto the fluorine doped Tin Oxide (FTO) glass substrate. The substrates were cleaned ultrasonically using detergent solution, acetone, and deionized water, respectively so as to ensure clean surface. The reaction bath for the deposition of zinc Selenide $(\mathrm{ZnSe})$ comprises Selenide IV oxide $\left(\mathrm{SeO}_{2}\right)$, Zinc tetraoxosulphate VI heptahydrate $\left(\mathrm{ZnSO}_{4} \cdot 7 \mathrm{H}_{2} \mathrm{O}\right)$, Potassium tetraoxosulphate VI $\left(\mathrm{K}_{2} \mathrm{SO}_{4}\right)$ and Tetraoxosulphate VI acid $\left(\mathrm{H}_{2} \mathrm{SO}_{4}\right)$. The $20 \mathrm{~cm}^{3}$ each of $\mathrm{SeO}_{2}$ and $\mathrm{ZnSO}_{4} .7 \mathrm{H}_{2} \mathrm{O}$ was measured into $150 \mathrm{ml}$ beaker using burette. $5 \mathrm{~cm}^{3}$ of $\mathrm{K}_{2} \mathrm{SO}_{4}$ was measured into the same $150 \mathrm{ml}$ beaker containing $\mathrm{SeO}_{2}$ and $\mathrm{ZnSO}_{4} \cdot 7 \mathrm{H}_{2} \mathrm{O}$ respectively to serve as the inert electrolyte which helps to dissociate the zinc ion from $\mathrm{ZnSO}_{4} \cdot 7 \mathrm{H}_{2} \mathrm{O}$. The solution was acidified with $5 \mathrm{~cm}^{3}$ of dilute $\mathrm{H}_{2} \mathrm{SO}_{4}$ which serves to adjust the $\mathrm{pH}$ value. The entire mixture was stirred with the glass rod to achieve uniformity. In each of the reaction baths prepared, a glass substrate and carbon electrode were connected to a DC power supply source and the voltage was maintained at $5 \mathrm{~V}$ for different time intervals.

\section{Results And Discussions}

Figures 1 shows the plot of optical absorbance as a function wavelength for ZnSenano films deposited at $1 \mathrm{~min}, 2 \mathrm{~min}, 3 \mathrm{~min}$, $4 \mathrm{~min}$ and $5 \mathrm{~min}$ at a constant voltage $(5 \mathrm{~V})$. From the graph, it was observed that as the wavelength of the incident radiation increases the absorbance of the films radiation decrease. It was also observed from the graph that sample Z5 deposited at $5 \mathrm{~min}$ has a steady increase and recorded the optical 
absorbance value of 0.273 while sample $\mathrm{Z} 1$ deposited at $1 \mathrm{~min}$ has the absorbance value of 0.151 . The optical absorption spectral of zinc selenidenano films reveals that the films grown at room temperature $(300 \mathrm{~K})$ and at varying deposition time of $1 \mathrm{mins}$, 2mins, 3 mins $4 \mathrm{mins}$ and $5 \mathrm{mins}$ have low absorbance in the infrared and ultraviolet region.

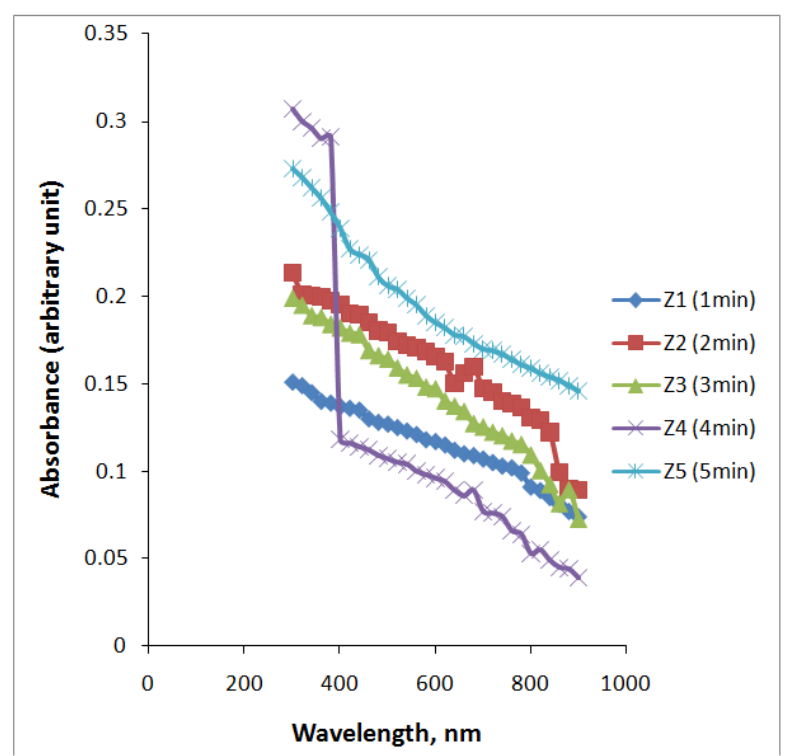

Figure 1: Plot of absorbance as a function of wavelength for zinc selenide films.

Figure 2 shows the plot transmittance (\%) as a function of wavelength for the Zinc selenide films deposited at $1 \mathrm{~min}, 2 \mathrm{~min}$, $3 \mathrm{~min}$, $4 \mathrm{~min}$ and $5 \mathrm{~min}$ at constant voltage (5V). From the graph, it was observed that sample Z4 deposited at $4 \mathrm{~min}$ recorded the transmittance value of $90 \%$ and sample Z1 deposited at $1 \mathrm{~min} 84 \%$. It was also observed that sample Z5 has a steady increase in the graph with a transmittance value from $53 \%-71 \%$. The graph also shows that transmittance has almost linear relationship with wavelength of incident radiation. It was observed that as the wavelength increases the transmittance of incident radiation increases.

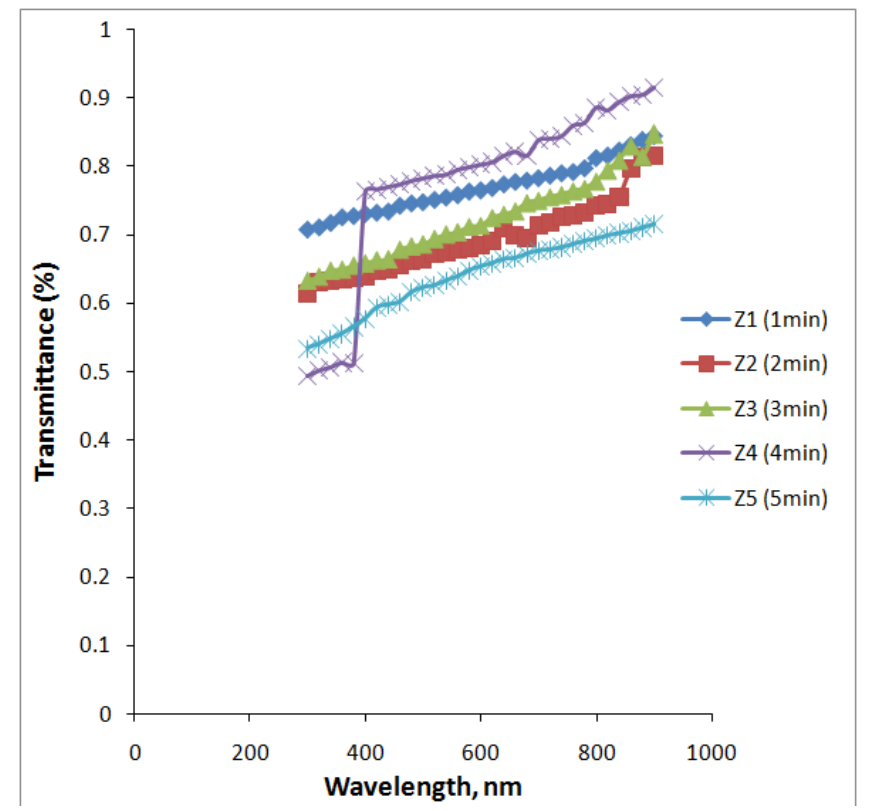

Figure 2: Plot of transmittance as a function of wavelength for zinc selenide films

Figure 3 shows the plot of reflectance as a function of wavelength for $\mathrm{ZnSe}$ films deposited at $1 \mathrm{~min}$, $2 \mathrm{~min}, 3 \mathrm{~min}$, $4 \mathrm{~min}$ and $5 \mathrm{~min}$ at constant voltage $(5 \mathrm{~V})$. From the graph, it was observed that as the wavelength increases the optical reflectance decreases. It was also observed from the graph that the reflectance of the films to the incident radiation was generally poor. Sample Z5 deposited at $5 \mathrm{~min}$ has a steady increase and recorded a reflectance value of 0.193 andsample $\mathrm{Z} 1$ deposited at $1 \mathrm{~min}$ recorded a reflectance value of 0.142 . 


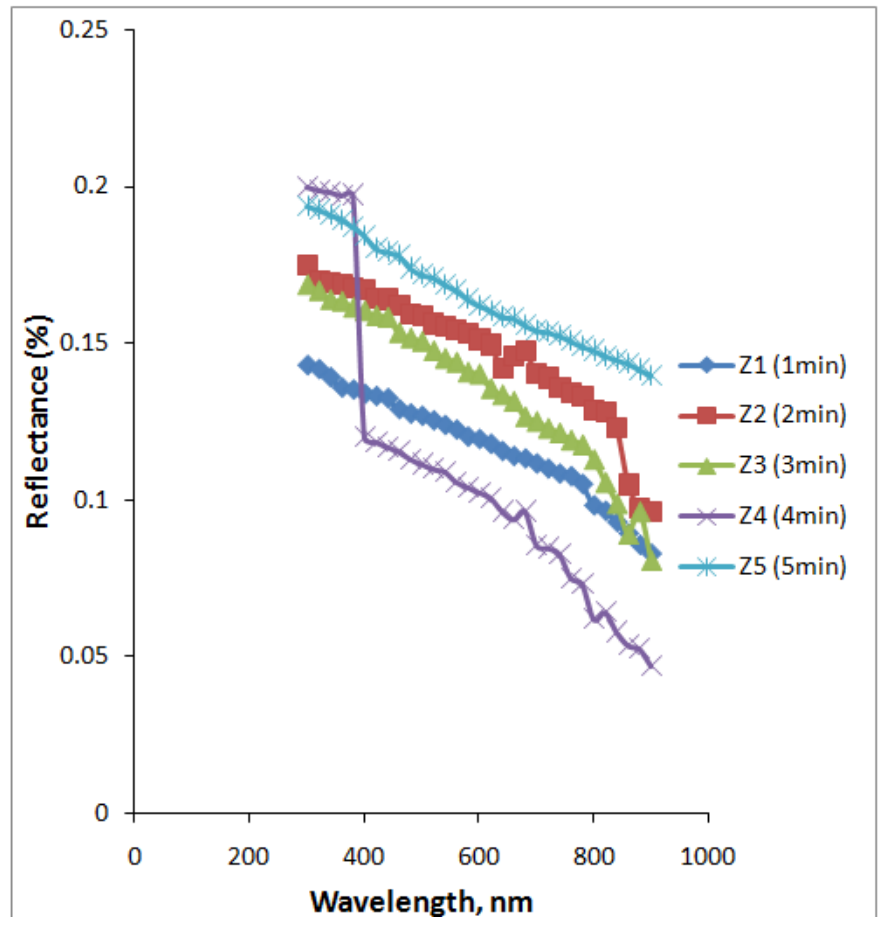

Figure 3: Plot of reflectance as a function of wavelength for zinc selenide films

The band gap energy and transition types were derived from mathematical processing of the data obtained from the optical absorbance as a function of wavelength with the following relationships for near edge absorption:

$\square=(\mathbf{h} v-\mathbf{E g})^{\mathbf{n} / \mathbf{2}}$,

Where $v$ is the frequency, $h$ is the Planck's constant, while $n$ carries the value of either 1 or 4 . The band gap could be obtained from a straight line plot of $\alpha^{2}$ as a function of hv; an extrapolation of the value of $\alpha^{2}$ to intercept the photon energy axis at zero point givesthe band gap energy of the deposited film. If a straight line graph is obtained from $n=1$, it indicates a direct transition between the states of the semiconductor, whereas the transition is indirect if a straight line graph is obtained from $n=4$ as shown in Figure 4. The band gap energy was found to $2.5 \mathrm{eV}$.

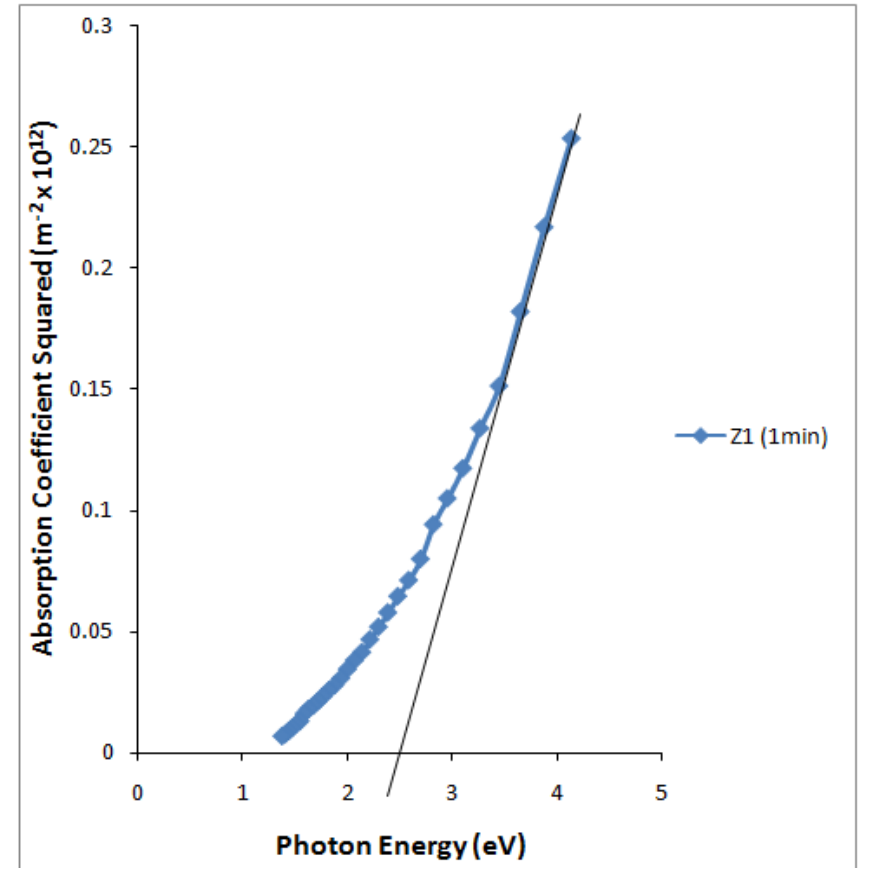

Figure 4: Plot of absorption coefficient squared as a function of photon energy 
The sheet resistivity and conductivity of the films were studied using a four point probe instrument (Model-T345). The calculated results for the sheet resistivity and electrical conductivity with their corresponding thickness are given in Table 1 . The result shows that $\mathrm{ZnSe}$ films have high sheet resistivity with a corresponding low electrical conductivity.The sheet resistivity current, voltage and thickness value were calculated using equation

$$
\mathrm{R}_{\mathrm{S}}=\frac{\pi}{\operatorname{In} 2} \frac{\mathrm{V}}{\mathrm{I}}(2)
$$

Where $\mathrm{R}_{\mathrm{S}}$ is the sheet resistivity, $\mathrm{I}$ is the current, $\mathrm{V}$ is the voltage.

Table 1: Electrical properties of ZnSe films

\begin{tabular}{|c|c|c|c|}
\hline SAMPLES & $\begin{array}{r}\text { THICKNESS, } \mathbf{t} \\
(\mathrm{nm})\end{array}$ & $\begin{array}{l}\text { SHEET RESISTIVITY, } \rho \\
(\Omega m)\end{array}$ & CONDUCTIVITY, $\sigma \quad(\Omega / m)^{-1}$ \\
\hline Z1 (1min) & 215 & $2.58 \times 10^{5}$ & $3.88 \times 10^{-6}$ \\
\hline $\mathrm{Z2}$ (2min) & 152 & $3.44 \times 10^{5}$ & $2.91 \times 10^{-6}$ \\
\hline Z3 (3min) & 155 & $4.08 \times 10^{5}$ & $2.45 \times 10^{-6}$ \\
\hline Z4 (4min) & 160 & $2.40 \times 10^{6}$ & $4.17 \times 10^{-7}$ \\
\hline Z5 (5min) & 164 & $5.49 \times 10^{4}$ & $1.82 \times 10^{-5}$ \\
\hline
\end{tabular}

X-ray diffractometer of wavelength (GBC eMMA, MoKal radiation of wavelength $(\lambda=0.7093 \AA$ ) was used for structural analysis of ZnSenano films. The X-ray diffraction patterns show a cubic structure which corresponds to (111) planes. See Table 2. These results agree with the reported values by other researchers [68]who reported the XRD preferred orientation of (111) planes. The values of the crystallite size were determined using Debye Scherer equation which is given in equation 3.

$$
\mathrm{D}=\frac{0.94 \lambda}{\beta \cos \theta}
$$

Where $\mathrm{D}$ is the crystallite size, $\boldsymbol{\beta}$ is the full-width at half maximum (FWHM), $\lambda$ is the wavelength of the $\mathrm{X}$-ray radiation and $\theta$ is the Bragg's diffraction angle at peak position in degree.

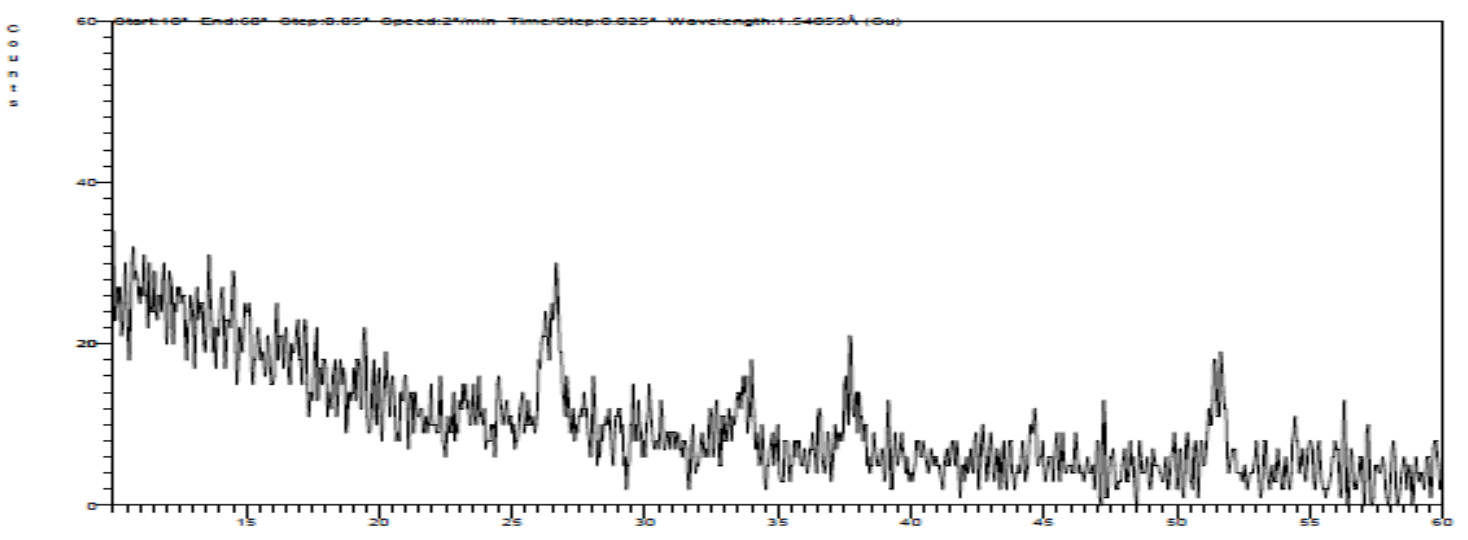

Figure 5 Zinc Selenide (ZnSe) Spectrum for 5V 1min

\begin{tabular}{|c|c|c|c|c|c|c|c|c|}
\hline Hk I & $\begin{array}{l}2 \theta \\
\text { (Degree) }\end{array}$ & $\begin{array}{l}\mathrm{d}(\AA \AA) \\
\text { standard }\end{array}$ & $\begin{array}{c}\text { Lattice } \\
\text { constant (Á) }\end{array}$ & $\begin{array}{l}\text { FWHM } \\
\text { (rad.) }\end{array}$ & $\begin{array}{l}\text { Grain size, } \\
\underset{(D)(\AA ́ A)}{x 10^{-10}}\end{array}$ & Dislocation density, & $\begin{array}{l}\text { Micro } \\
\text { strain }\end{array}$ & $\varepsilon$ \\
\hline 111 & 23.642 & 3.760 & \multirow[t]{4}{*}{5.852} & 0.0240 & 6.164 & 0.028 & 1.216 & \\
\hline 220 & 29.554 & 3.020 & & 0.0240 & 6.240 & 0.023 & 1.890 & \\
\hline 311 & 35.743 & 2.510 & & 0.0240 & 6.414 & 0.016 & 3.906 & \\
\hline 440 & 40.414 & 2.230 & & 0.0240 & 6.429 & 0.016 & 3.906 & \\
\hline
\end{tabular}

Table 2: Structural parameters of ZnSe film

\section{Conclusions}

Electrodeposition techniquewas used to deposit zincselenidenanofilms on fluorine tin oxide (FTO) glass substrate. The absorbance and reflectance of the films to incident radiation were found to be low with high transmittance values. The studied properties were found to depend on time and voltage of the deposition. The resistivity of the films was observed to be high with low conductivity. The thickness of the deposited films was found to be in the nano range. The structure of the films was found to be cubic in nature with lattice constant of5.852A.All these desirable properties made the semiconductor material $(\mathrm{ZnSe})$ to be a good candidate for applications in photovoltaic and opto-electronic devices 


\section{Acknowledgment}

The authors are grateful to the Staff of Engineering and Material Development Institute (EMDI) and National Agency for Science and Engineering Infrastructure (NASENI) Akure,Ondo State were the characterization was done.

\section{References}

[1]. Bedir M, Oztas M, Bakkaloglu O. F and Ormanci R, (2005). Qouted by Kassim, A., Tee, T. W., Min, H. S., Monohorn, S., \&Nagalingam, S. (2010). Effect of bath temperature on the chemical bath deposition of PbSe thin films. Kathmandu University Journal of Science, Engineering and Technology, 6(2), 126-132.

[2]. Gallian, A, Fedorov, VV, Mirov, SB, Badikov, VV, Galkin, SN, Voronkin, EF, Lalayants, AI: Hot-pressed ceramic Cr2+: ZnSe gain-switched laser. Opt Express 14(24), 11694 (2006)

[3]. Okereke, NA, Ekpunobi, AJ: ZnSe buffer layer deposition for solar cell application. Journal of Non-Oxide Glasses 3(1), 31 (2011)

[4]. Rao, CNR, Vivekchand, SRC, Biswas, K, Govindaraj, A: Synthesis of organic nanomaterials. Dalton Trans 34, 3728 (2007)

[5]. Hsiao, CH, Hung, SC, Chih, SH, Wang, SB, Cheng, YC, Huang, BR, Young, SJ, Chang, SJ: ZnSe/ZnSeTesuperlatticenanotips. Nanoscale Res Lett 5, 930 (2010)

[6]. khioya, I. L and A. J. Ekpunobi, (2014): Effect of deposition period and pH on Electrodeposition Technique of Zinc Selenide Thin Films. Journal of Nigeria Association of Mathematical Physics. Vol. 28, 2, 281-288

[7]. Okereke, N. A., Ekpunobi, A. J., (2011). ZnSe buffer layer deposition for solar cell application. Journal of Non-Oxide Glasses, 3 (1) 31-36.

[8]. Okereke, N. A., Ezenwa, I. A and Ekpuobi, A. J., (2011).Effect of thickness on the optical properties of ZnSe thin films, Journal of Oxide Glass. 3, 105-111. 